\title{
New partial dentaries of amphitheriid mammalian Palaeoxonodon ooliticus from Scotland, and posterior dentary morphology in early cladotherians
}

\author{
Elsa Panciroli, Roger B.J. Benson, and Richard J. Butler \\ Acta Palaeontologica Polonica 63 (2), 2018: 197-206 doi:https://doi.org/10.4202/app.00434.2017
}

We describe two partial dentaries of mammals from the Middle Jurassic of Scotland. They belong to the early cladotherian Palaeoxonodon ooliticus. These dentaries comprise the first specimen of $P$. ooliticus ever found-although its significance was initially unrecognised so it remained undescribed until now - and the most recently discovered specimen, found during fieldwork in 2017. The new specimen preserves part of the coronoid process of the dentary, previously unknown for $P$. ooliticus, demonstrating the presence of a deep masseteric fossa, with a prominent crest enclosing the fossa anteriorly, and a masseteric foramen, located in the masseteric fossa on the buccal surface of the dentary. On the lingual surface, the mandibular foramen is offset from the Meckel's sulcus, and positioned below the alveolar plane. These morphologies allow an updated analysis of the phylogenetic position of $P$. ooliticus, confirming a sister-taxa relationship between Palaeoxonodon and Amphitherium . The position of the mandibular foramen, and the slight extension of the masseteric fossa into the body of the dentary are new autapomorphies for Palaeoxonodon.

Key words: Mammalia, Cladotheria, Palaeoxonodon ooliticus, Jurassic, Bathonian, Kilmaluag Formation, UK, Scotland.

Elsa Panciroli [elsa.panciroli@ed.ac.uk], School of Geosciences, University of Edinburgh, Grant Institute, Kings Buildings, Edinburgh, EH9 3FE, UK; National Museum of Scotland, Chambers St, Edinburgh, EH1 1JF, UK. Roger B.J. Benson [roger.benson@earth.ox.ac.uk], Department of Earth Sciences, University of Oxford, South Parks Road, Oxford, OX1 3AN, UK. Richard J. Butler [r.butler.1@bham.ac.uk], School of Geography, Earth and Environmental Sciences, University of Birmingham, Birmingham, B15 2TT, UK. 
Attribution License (for details please see creativecommons.org), which permits unrestricted use, distribution, and reproduction in any medium, provided the original author and source are credited.

\footnotetext{
FaF Full text $(501.0 \mathrm{kB})$ ।

Far Supplementary file $(81.6 \mathrm{kB})$
} 